\title{
Fico muito ansiosa: ansiedade, crenças e ações de uma aluna brasileira sobre a aprendizagem de inglês como língua estrangeira
}

\author{
Karolina Morais \\ Secretaria de Educação do Distrito Federal \\ karolina.morais@edu.se.df.gov.br \\ Yûki Mukai \\ Universidade de Brasília \\ yuki@unb.br
}

\section{Resumo}

Esta pesquisa teve como objetivo identificar a ansiedade, as crenças e as ações de uma aluna brasileira de inglês como língua estrangeira (LE) sobre a língua inglesa e sua aprendizagem, além de analisar as relações entre ansiedade, crenças e ações desta aluna. Esta é uma pesquisa qualitativa de cunho interpretativista com foco na abordagem contextual dos estudos de crenças, utilizando o método de estudo de caso intrínseco. Os resultados da pesquisa mostraram que a participante apresenta ansiedade ao realizar atividades orais em dupla, grupos menores ou com a turma inteira em provas de produção e compreensão orais, além de ter medo de ser corrigida pelo professor na frente dos colegas. Apesar de seus medos, a participante acredita na eficácia de atividades orais em grupos ou duplas e no feedback corretivo para o desenvolvimento da aprendizagem da LE. Embora mantenha essas crenças, ela age no intuito de evitar participar dessas tarefas orais, assim não precisa falar ou ser corrigida pelo professor e, portanto, não se sentirá ansiosa.

Palavras-chave: Ansiedade. Crenças. Ações. Aprendizagem. Língua Estrangeira. Língua Inglesa.

\begin{abstract}
This research aimed to investigate the anxiety, beliefs and actions of a Brazilian student of English as a foreign language (FL) about the English language and its learning, in addition to analyzing the relationship between the participant's anxiety, beliefs, and actions. This is a qualitative research of an interpretive nature with a focus on the contextual approach to the study of beliefs, using the intrinsic case
\end{abstract}


Fico muito ansiosa: ansiedade, crenças e ações...

study method. The results of this research showed that the participant presents anxiety when performing oral activities in pairs, smaller groups or with the whole class, in tests of oral production and oral comprehension and she is afraid of being corrected by the teacher in front of her classmates. Despite her fears, the participant believes in the effectiveness of oral activities in groups or pairs and in corrective feedback for the development of FL learning. In spite of those beliefs, she acts in a way as to avoid participating in those oral tasks, so that she does not need to speak or be corrected by the teacher, thus, she will not feel anxious.

Keywords: Anxiety. Beliefs. Actions. Learning. Foreign Language. English Language.

\section{Introdução}

Por que algumas pessoas se destacam na aprendizagem de línguas estrangeiras ${ }^{1}$ (LE), demonstrando certa facilidade, enquanto outras parecem não se desenvolver no estudo da língua? (LARSEN-FREEMAN; LONG, 1991). A resposta para essa pergunta está nas diferenças individuais: cada aprendiz conta com determinados fatores que irão influenciar sua forma de aprender línguas, a saber, fatores cognitivos, afetivos e sociais (CONCEIÇÃO, 2004). Em verdade, o processo de ensino-aprendizagem em si conta com uma complexidade de elementos que estão interligados e agem de forma diferente em cada indivíduo, grupo e contexto (BATTISTELLA, 2016).

O foco nos estudos dos fatores individuais mostra-nos que os pesquisadores estão olhando cuidadosamente as ideias e as concepções de alunos e professores no processo de ensino-aprendizagem de línguas (BARCELOS, 2001). Isso ocorre devido a uma mudança na concepção de aprendizagem de língua, que antes salientava a importância do produto dessa aprendizagem e agora passa a considerar a importância do processo (BARCELOS, 2004).

Um dos fatores individuais de grande relevância é o estudo das crenças dos aprendizes, uma vez que esse tipo de investigação permite entender de onde vêm as crenças dos alunos e de que maneira essas crenças

\footnotetext{
${ }^{1}$ Neste artigo, utilizamos os termos segunda língua (L2) e língua estrangeira (LE) de forma intercambiável.
} 
influenciam as estratégias de aprendizagem utilizadas por eles (HORWITZ, 1987; CONCEIÇÃO, 2004), a forma como agem e de que maneira elas podem auxiliar na diminuição ou no desaparecimento da ansiedade de aprender uma LE (BARCELOS, 2007).

Além do mais, no processo de aquisição de uma nova língua, o aluno pode encontrar-se em condições desconfortáveis, visto que mesmo sem ser competente linguisticamente no idioma que está estudando ele tem de usá-lo para comunicação em sala de aula e para solucionar possíveis tarefas e problemas que nela apareçam (BATTISTELLA, 2016). Em situações como essas, os aprendizes começam a sentir emoções negativas, tais como ansiedade.

A ansiedade é uma variável afetiva de grande importância para compreender o processo de aprendizagem de LE, visto que, muitas vezes, é ela que determina como o sujeito irá agir nas diferentes situações a que ele for exposto (GARDNER; MACINTYRE, 1993), seja na interação com colegas, seja numa entrevista de emprego, ou em sua performance na prova oral, por exemplo. Dessa forma, esse fator afetivo pode funcionar como um impedimento para a aprendizagem dos adultos. Portanto, enfatizamos a importância de estudar a ansiedade, as crenças e as ações de uma aluna brasileira de inglês como LE.

Para a realização desta investigação, elegemos uma participante brasileira que nos chamou a atenção por, em suas conversas com sua professora de inglês, demonstrar ansiedade e um certo bloqueio em relação à aprendizagem do inglês. Este artigo é um recorte de um estudo que resultará em uma dissertação de mestrado.

Assim, os objetivos desta pesquisa são: identificar a ansiedade, as crenças e as ações da participante sobre a língua inglesa e sua aprendizagem; analisar as relações entre a ansiedade, as crenças e as ações da participante. Considerando os objetivos citados, procuramos responder às seguintes perguntas de pesquisa: em que a aluna apresenta ansiedade e quais são suas crenças e ações quanto à língua inglesa e sua aprendizagem? Qual a relação entre ansiedade, crenças e ações dessa aluna quanto à aprendizagem de inglês? 
Fico muito ansiosa: ansiedade, crenças e ações...

\section{Fundamentação teórica}

Para responder às perguntas de pesquisa, discutiremos os construtos de filtro afetivo (KRASHEN, 1982, 1985, 2004), ansiedade (ARNOLD; BROWN, 2000; GARDNER; MACINTYRE, 1993; GREGERSEN et al., 2014; HORWITZ et al., 1986; MACINTYRE, 2017; RUBIO ALCALÁ, 2004) e crenças (BARCELOS, 2001, 2004, 2006, 2007; HORWITZ, 1987; KALAJA; BARCELOS, 2016), a seguir.

Krashen (1982, p. 1) aborda "o relacionamento entre a prática do ensino de segunda língua e o que se sabe a respeito do processo de aquisição de segunda língua" (tradução nossa). ${ }^{2}$ Para isso, apresenta cinco hipóteses acerca desse tema: a) distinção entre aquisição/aprendizagem; b) a hipótese da ordem natural; c) a hipótese do monitor; d) a hipótese do input ou da compreensão (KRASHEN, 2004); e e) a hipótese do filtro afetivo. Discorremos apenas acerca da hipótese do filtro afetivo, pois é a que nos interessa para este artigo.

Krashen (1985) define o filtro afetivo como um obstáculo mental que impossibilita que os aprendizes usem integralmente o input (insumo) compreensível recebido para adquirir a língua. Essa hipótese mostra como fatores afetivos podem influenciar o processo de aquisição de segunda língua. Dessa forma, se os aprendizes estão desmotivados, ansiosos, inseguros e com baixa autoestima, provavelmente não irão procurar por mais input (condição mínima para aquisição de L2) e estarão com o filtro afetivo alto. Se o filtro afetivo estiver alto, o input não chegará à parte do cérebro responsável pela aquisição, o Dispositivo de Aquisição da Linguagem (DAL), e, assim, não haverá aquisição.

O filtro afetivo funciona da seguinte maneira: o aprendiz é exposto ao input compreensível $(i+1)$, esse input passa pelo filtro afetivo e, pelo filtro afetivo estar baixo, o input consegue alcançar o DAL e a aquisição acontece. Krashen (1982) mostra o papel primordial que o input realiza, porém o autor alerta que o aprendiz pode ter acesso a uma quantidade alta

\footnotetext{
${ }^{2}$ Do original: The relationship between second language teaching practice and what is known about the process of second language acquisition. Todas as traduções deste artigo foram feitas pelos autores.
} 
de input compreensível e, mesmo assim, a aquisição não ocorrer devido ao fato de o filtro afetivo estar alto.

O filtro afetivo é composto de variáveis afetivas. Estas podem ser divididas em três categorias: motivação, autoconfiança e ansiedade (KRASHEN, 1982). Assim, aprendizes com motivação mais alta deverão ter melhores resultados do que os aprendizes que não estão motivados. Os aprendizes que são autoconfiantes tendem a apresentar resultados positivos na aquisição de segunda língua. O mesmo ocorre quando o aluno apresenta baixa ansiedade, tanto na sala de aula quanto na vida pessoal. Isso ocorre porque o filtro afetivo se encontra baixo e, assim, permite que o input alcance as partes do cérebro responsáveis pela aquisição (hipótese da compreensão) (KRASHEN, 2004).

A ansiedade, por sua vez, é uma das características das variáveis afetivas dos indivíduos que influenciam a maneira como o ser humano responderá a qualquer situação (GARDNER; MACINTYRE, 1993), inclusive à aprendizagem de línguas. Horwitz et al. (1986) afirmam que os alunos ansiosos demonstram apreensão, preocupação ou, até mesmo, medo e apresentam dificuldade em se concentrar, a memória falha, eles transpiram e têm palpitações. Gregersen et al. (2014) afirmam que esse tipo de emoção negativa que o aluno experiencia pode delimitar seu esforço e comportamento. Dessa maneira, como resposta à ansiedade, esses alunos começam a faltar às aulas e a adiar as tarefas de casa, atitudes chamadas de comportamento de evitamento, ou podem agir completamente ao contrário, começando a estudar compulsivamente (HORWITZ et al., 1986).

Arnold e Brown (2000) acrescentam que a ansiedade pode ser tão negativa que chega a causar danos ainda maiores, incluindo estragos no lóbulo pré-frontal do cérebro, fazendo com que a memória não funcione adequadamente, o que diminui a capacidade de aprendizagem. Por isso, materiais e técnicas eficientes de ensino podem se tornar inúteis quando existem reações afetivas negativas (ARNOLD; BROWN, 2000). Além disso, MacIntyre (2017) defende que a ansiedade de língua estrangeira é um estado interno e socialmente construído, visto que essa emoção é motivada não só por fatores psicológicos, cognitivos e emocionais, mas, também, pela situação na qual o aprendiz está inserido, com a presença de outras pessoas.

Gardner e MacIntyre (1993) definem a ansiedade de língua como 
Fico muito ansiosa: ansiedade, crenças e ações...

a apreensão experimentada quando uma situação requer o uso de uma segunda língua na qual o indivíduo não é totalmente proficiente. $E$, portanto, visto como um traço de personalidade estável que se refere à propensão para um indivíduo reagir de maneira nervosa ao falar, ouvir, ler ou escrever na segunda lingua (GARDNER; MACINTYRE, 1993, p. 05). ${ }^{3}$

Horwitz et al. (1986) apontam três componentes da ansiedade de língua estrangeira: 1) apreensão comunicativa; 2) ansiedade de provas e 3) medo de avaliação negativa. A apreensão comunicativa diz respeito à insegurança caracterizada pelo medo ou pela ansiedade de falar com outras pessoas em dupla, grupo ou em público. Essa insegurança, ao se expressar, pode estar ligada ao fato de os aprendizes apresentarem recursos linguísticos limitados, o que os impossibilita de passar as mensagens satisfatoriamente (SANTOS; BARCELOS, 2018). A ansiedade de provas é outra característica comum à ansiedade de língua estrangeira e refere-se ao medo de ser reprovado ou falhar (MCCROSKEY, 1977 apud HORWITZ et al., 1986) no teste escrito ou oral. O teste oral pode causar ainda mais ansiedade, pois estimula a ansiedade de provas e a apreensão comunicativa (HORWITZ et al., 1986). O último componente da ansiedade de LE, de acordo com Horwitz et al. (1986), é o medo de avaliação negativa, que corresponde à apreensão de avaliação negativa em qualquer situação social de uso da língua, seja em uma entrevista de emprego, seja em uma atividade oral em sala de aula. Ademais, Rubio Alcalá (2004) discute outros dois componentes da ansiedade de língua estrangeira. O primeiro é a ansiedade de realização, ${ }^{4}$ que remete ao medo de não conseguir alcançar o objetivo inicialmente proposto, medo de falhar ou de ser avaliado com resultados desfavoráveis. O segundo componente que o autor especifica é a ansiedade receptiva, que é o receio de não compreender mensagens.

\footnotetext{
${ }^{3}$ Do original: the apprehension experienced when a situation requires the use of a second language with which the individual is not fully proficient. It is, therefore, seen as a stable personality trait referring to the propensity for an individual to react in a nervous manner when speaking, listening, reading or writing in the second language.
}

${ }^{4}$ No original: ansiedad de logro. 
Concordamos com Horwitz et al. (1986) quando afirmam que a ansiedade de língua estrangeira não é somente formada pelos componentes citados anteriormente. Ela é também caracterizada como um conjunto específico de percepções de si mesmo, sentimentos, crenças e atitudes relativos a aprender um idioma em sala de aula resultante da particularidade do processo de aprendizagem de línguas (HORWITZ et al., 1986, p. 128). Essas autopercepções, crenças e sentimentos acabam por influenciar a produção verbal, levando-a a diminuir, e fazem com que os alunos tenham dificuldade em aprender conteúdos básicos ou tenham receio de se voluntariar para responder a algo em sala de aula (GARDNER; MACINTYRE, 1993), afetando negativamente a aprendizagem de LE.

Por fim, as crenças são um dos fatores mais relevantes que influenciam como os aprendizes atuarão na língua estrangeira que estão aprendendo (KALAJA; BARCELOS, 2016). Barcelos (2006, p. 151) as define como:

uma forma de pensamento, como construções da realidade, maneiras de ver e perceber o mundo e seus fenômenos, coconstruídas em nossas experiências resultantes de um processo interativo de interpretação e (re)significação (BARCELOS, 2006, p. 151).

Assim, as crenças têm origem nas experiências dos aprendizes de LE e concepções de outras pessoas que também fazem parte do processo de ensino-aprendizagem, como os professores, os pais e os colegas (KALAJA; BARCELOS, 2016).

Nos estudos atuais, o contexto e a relação entre crenças e ações dos alunos e professores são levados em consideração (BARCELOS, 2004). É reconhecido que as crenças são dinâmicas, pois dependem do contexto, ou seja, "elas podem variar ou permanecer estáveis através do tempo e do espaço, ou até mesmo estarem em conflito mutuamente" (KALAJA; BARCELOS, 2016 p. 10). ${ }^{5}$ Além disso, atualmente os estudos sobre crenças estão se expandindo de forma mais holística, sendo investigadas

${ }^{5}$ Do original: they can vary or remain stable across time and space, and even be mutually conflicting. 
Fico muito ansiosa: ansiedade, crenças e ações...

junto com outros construtos, tais como identidade e emoções (BARCELOS, 2013).

A importância do estudo de crenças surge na Linguística Aplicada a partir do momento em que se passa a considerar o ensino-aprendizagem de línguas do ponto de vista do processo e não de língua como produto (BARCELOS, 2004). Assim, estudar as crenças dos alunos auxilia-nos a entender suas ações com relação às suas estratégias de aprendizagem e os ajudam a controlar (ou não) a ansiedade que, por vezes, aparece como obstáculo para os alunos ao aprender uma LE (BARCELOS, 2007).

\section{Metodologia}

\subsection{Método e natureza da pesquisa}

Esta é uma pesquisa qualitativa (ANDRÉ, 2012; PRODANOV; FREITAS, 2013) de natureza aplicada (PRODANOV; FREITAS, 2013) e exploratória (GIL, 2008; PRODANOV FREITAS, 2013) do tipo etnográfico e um estudo de caso intrínseco (STAKE, 2005; YIN, 2015) por se realizar com uma única participante, que nos chamou a atenção pela forma como se dava a relação entre o que ela acreditava, como agia e sua experiência com a aprendizagem da língua inglesa.

Utilizamos como base os fundamentos da pesquisa sobre crenças com abordagem contextual (BARCELOS, 2001; VIEIRA-ABRAHÃO, 2006), que objetiva compreender não somente as crenças dos aprendizes, mas também suas ações em contextos específicos, considerando suas experiências anteriores de aprendizagem de língua e entendendo os aprendizes como agentes sociais que interagem nesses contextos (BARCELOS, 2004), sem julgar suas crenças e ações como corretas ou errôneas.

\subsection{Contexto da pesquisa e a participante}

A pesquisa foi realizada com uma aluna de um Centro Interescolar de Línguas (CIL) do Distrito Federal (DF). Os CILs são escolas públicas de natureza especial, as quais oferecem cursos livres de inglês, espanhol, 
francês, japonês e alemão à comunidade em geral e aos alunos do ensino básico da rede pública do DF.

O CIL em questão conta com dois tipos de cursos: o pleno e o específico. O pleno tem duração de cinco ou seis anos, e o específico dura três anos. Ambos os cursos têm o objetivo de desenvolver as habilidades de produção e compreensão orais e escritas do aluno.

A participante desta pesquisa é Beatriz (nome fictício). Ela é uma aluna brasileira de inglês como língua estrangeira em um CIL do Distrito Federal.

Beatriz tem 29 anos e sua única experiência com a aprendizagem de inglês antes de estudar no CIL foi no ensino básico. Ela está no quarto semestre do curso específico de inglês, porém está refazendo o específico 3, isto é, o último nível que cursou, porque foi reprovada por falta e, consequentemente, por nota.

A aluna nos chamou atenção, pois, em suas conversas com sua professora, sempre se classificava como "péssima no inglês", falava que "seu coração ia sair pela boca" quando precisava se comunicar ou responder algo usando a LE, falava que "não conseguia aprender inglês" e tinha muito receio de errar. No primeiro semestre de 2020, devido à sua necessidade de revisar o que já havia sido estudado anteriormente, decidiu se matricular em um curso de inglês particular, começando do nível 01 e está estudando nos dois cursos simultaneamente.

\subsection{Instrumentos para a coleta de dados}

Utilizamos múltiplos instrumentos para a coleta dos dados, são eles: dois questionários, uma narrativa visual e uma entrevista semiestruturada.

Um questionário muito utilizado nos estudos de crenças é o BALLI (Beliefs about Language Learning Inventory). ${ }^{6}$ Uma das funções desse instrumento é compreender a crença dos alunos e como essas crenças

\footnotetext{
${ }^{6}$ Este questionário é composto por perguntas em escala na qual o aprendiz teria de escolher entre as opções (1) concorda plenamente; (2) concorda; (3) não tem opinião a respeito; (4) não concorda; (5) discorda plenamente.
} 
Fico muito ansiosa: ansiedade, crenças e ações...

influenciam a estratégia de aprendizagem utilizada por eles (HORWTIZ, 1987).

Para este trabalho, o BALLI adaptado (ver apêndice A) foi aplicado com o intuito de coletar as crenças que Beatriz apresenta acerca de sua aprendizagem de inglês. Esse instrumento foi adequado quanto ao número de enunciados, visto que no original há 34 afirmativas e foram aplicadas apenas 18 dessas. Além disso, foram ajustados dois termos do BALLI original, isto é, foram substituídas as expressões "língua estrangeira" por "inglês" e "falar inglês com americanos" por "falar inglês com nativos".

Outro questionário utilizado foi a Escala de Ansiedade de Sala de Aula de Língua Estrangeira (EASALE) ${ }^{7}$ (ver apêndice B). Esse questionário foi construído para identificar os alunos que sentiam ansiedade na aula de LE (HORWITZ et al., 1986). Nesta pesquisa, a EASALE, adaptada com relação aos termos usados, ${ }^{8}$ foi usada para identificar os tipos de ansiedade que Beatriz sente nas aulas de inglês.

A narrativa visual, também denominada desenhos (VIEIRAABRAHÃO, 2006), vem sendo adotada na Linguística Aplicada como forma de compreender fatos ocorridos, experiências subjetivas dos alunos ou professores e como maneira de identificar discursos sobre o aprendizado ou ensino da língua produzidos pelos alunos ou pelos professores (KALAJA et al., 2013).

$\mathrm{O}$ desenho, com o tema "o que a aprendizagem de inglês representa para mim" (ver Anexo A), foi utilizado neste estudo para compreender melhor o que é a aprendizagem de inglês para Beatriz, demonstrando também suas expectativas e sentimentos.

A entrevista "permite a captação imediata e corrente da informação desejada" (LÜDKE; ANDRÉ, 1986, p. 34), bem como possibilita que algo seja corrigido, esclarecido ou adaptado (LÜDKE; ANDRÉ, 1986).

Nesta pesquisa, a entrevista semiestruturada foi utilizada com o objetivo de compreender melhor questões que os três últimos instrumentos deixaram em aberto e com a finalidade de realizar a triangulação dos dados.

\footnotetext{
${ }^{7} \mathrm{O}$ termo original em inglês é Foreign Language Classroom Anxiety Scale (FLCAS).

${ }^{8}$ Onde havia o termo "língua estrangeira" substituímos por "inglês" ou "língua inglesa".
} 
As perguntas da entrevista basearam-se em tópicos levantados nos questionários e na narrativa visual.

\subsection{A coleta dos dados}

A coleta de dados foi realizada no primeiro semestre de 2020. Inicialmente, no dia 20 de abril pedimos que Beatriz preenchesse os questionários fechados (BALLI e EASALE adaptados). Logo após, entre os dias 27 de abril e 3 de maio, a aluna desenhou o que a aprendizagem de inglês significava para ela. Por fim, usamos a entrevista semiestruturada para tirar dúvidas relacionadas às respostas dos instrumentos anteriores. A entrevista foi dividida em duas sessões. Na primeira conversamos sobre as respostas levantadas nos dois questionários fechados, e na segunda abordamos os dados coletados na narrativa visual. Cada sessão da entrevista durou cerca de 30 minutos. A primeira e a segunda sessão da entrevista foram realizadas em 5 e 12 de maio, respectivamente.

\subsection{Procedimento para a análise de dados}

Os dados coletados foram agrupados em categorias conceituais (CRESWELL, 2009) por meio da codificação qualitativa e indutiva, levando em consideração os objetivos e as perguntas de pesquisa. Assim, nossa análise dos dados seguiu o roteiro abaixo:

a. coleta de dados no que se refere à ansiedade, às crenças e às ações da participante;

b. descrição da ansiedade, das crenças e das ações;

c. identificação da ansiedade, das crenças e das ações;

d. análise de conteúdo (BARDIN, 1977);

e. categorização e codificação indutiva da ansiedade, das crenças e das ações;

f. triangulação dos dados coletados (PRODANOV; FREITAS, 2013);

g. análise sobre as relações entre a ansiedade, as crenças e as ações da participante. 
Fico muito ansiosa: ansiedade, crenças e ações...

$\mathrm{Na}$ próxima seção apresentamos os dados obtidos, discutindo-os para responder às nossas perguntas de pesquisa.

\section{ANÁLISE E DISCUSSÃO DOS DADOS}

\subsection{BALLI adaptado}

Os resultados do questionário BALLI adaptado mostraram que, apesar de Beatriz considerar a língua inglesa difícil (04), ${ }^{9}$ ela possui o desejo (18) e acredita que vai conseguir falá-la bem (05). Ela fica com vergonha de praticar inglês com outras pessoas (11), e mesmo discordando que não se deve falar nada na língua até que saiba falar corretamente, essa atitude de se sentir envergonhada pode impedi-la de se expressar em inglês, mostrando uma ação de bloqueio ao tentar usar a língua para se comunicar.

Por um lado, Beatriz acredita que é menos complicado para as crianças aprenderem línguas (01), e que, além das crianças, algumas pessoas têm uma competência especial para aprendê-las (02). Por outro lado, apesar de existirem pessoas com maior aptidão para línguas, ela defende que todos podem aprender uma LE (17).

Por último, Beatriz discorda que a gramática (13) ou a tradução para a língua materna (16) seja o mais importante quando se aprende uma LE. Pelo contrário, ela acredita que o vocabulário é a parte mais importante de aprender uma língua (13). Conforme o resultado deste questionário, essa crença de Beatriz quanto à gramática, à tradução e ao vocabulário pode expor sua ação de focar mais nos estudos do vocabulário do que nos outros dois para concretizar sua aprendizagem.

\subsection{EASALE adaptada}

Os dados coletados na EASALE adaptada apontam que Beatriz se sente mais tensa e nervosa na aula de inglês do que em outras aulas que

\footnotetext{
${ }^{9}$ Os números em parênteses referem-se aos enunciados do questionário BALLI adaptado.
} 
frequenta (26). ${ }^{10}$ Além disso, Beatriz assinalou que nunca se sente segura quando tem de falar durante a aula (01), ou seja, discorda que se sinta confiante quando se expressa em inglês na aula (18), entrando em pânico quando tem de fazê-lo sem ter se preparado previamente (09).

Ela mostrou, também, que fica constrangida quando precisa falar na aula de inglês (24) e chega a tremer quando sabe que vai ser chamada (03) ou que o professor fará perguntas para as quais ela não tenha se preparado antes (33), tanto por receio de cometer erros (02) quanto por receio de os outros alunos rirem dela. Por isso fica tão nervosa a ponto de se esquecer das coisas que sabe (12) e sente o coração batendo forte quando pressupõe que vai ser chamada na aula (20).

Outros motivos de ansiedade para Beatriz na aula são não compreender cada palavra que o professor diz (29) e as provas, pois ela não se sente à vontade durante estas (08), tendo em vista que se preocupa com as consequências de ser reprovada em inglês (10).

Apesar de todas essas emoções sentidas por Beatriz durante a aula, ela não opinou sobre ficar com receio de que o professor esteja pronto para corrigir todos os seus erros (19), mostrando, talvez, que não se importa em ser corrigida e discordou do enunciado sobre ter vontade de faltar às aulas (17), demonstrando que ela não apresenta comportamento do evitamento (HORWITZ et al., 1986). Além disso, ela apontou que uma maneira de ajudá-la na aprendizagem seria estudando mais, visto que não acredita que quanto mais estuda, mais confusa fica (21), e em razão de ser necessário aprender muitas regras do inglês para falar (30).

\subsection{Narrativa visual e entrevista semiestruturada}

Para compreender melhor e analisar a relação entre ansiedade, crenças e ações da participante sobre a aprendizagem de língua inglesa, separamos os dados coletados em duas categorias: "frustração e apreensão sobre a oralidade" e "medo de avaliação negativa e ansiedade de provas".

\footnotetext{
${ }^{10}$ Os números em parênteses referem-se aos enunciados da EASALE adaptada.
} 
Fico muito ansiosa: ansiedade, crenças e ações...

\subsubsection{Frustração e apreensão sobre a oralidade}

Beatriz demonstrou que sente grande ansiedade quando tem de falar na língua inglesa. Essa ansiedade concretiza-se por meio de comportamentos psicológicos, tais como agonia, suor e frio na barriga. Esses sintomas são destacados em Horwitz et al. (1986), que acrescentam que, além dessas características, os alunos também podem apresentar dificuldade de concentração e palpitações, conforme mostra o excerto abaixo:

Excerto 1. Sintomas de ansiedade.

[quando vou ser chamada para falar na aula de inglês] me dá uma agonia, um trem assim na barriga, um suado na mão (entrevista, 5 de maio de 2020).

Beatriz afirma que a ansiedade é ainda maior quando ela tem de falar para a turma. Essa ansiedade pode ser explicada pelo medo de errar e de os alunos rirem dela, demonstrados em sua resposta à EASALE adaptada, e à vergonha de falar inglês com outras pessoas, conforme a participante assinalou no BALLI adaptado. Ela relata, então, uma atividade de prática oral que a professora pede que eles façam com certa frequência.

Excerto 2. Ansiedade de falar para a turma toda.

A professora, uma vez por semana, ela pede pra falar pra turma. Pense num sofrimento... Toda vez que eu vou falar ninguém entende nada (risos). [...]. Você tem que falar pra turma. Aí ela [a professora] fala, sei lá "é pra falar sobre minha casa", eu vou pegar o vocabulário e vou falar sobre os móveis, sobre o que eu faço, não sei o quê. Aí tem que falar pra turma. Aí eu fiz só uma vez, quando foi a segunda vez que era pra fazer eu faltei, com medo (entrevista, 5 de maio de 2020).

Sua ansiedade para apresentar o trabalho para a turma foi tão acentuada que gerou uma ação: faltar à aula (comportamento do evitamento) para não ter de falar na frente do grupo inteiro. Nesse excerto podemos perceber que a ansiedade, além de um fator psicológico, é, também, socialmente construída (MACINTYRE, 2017). Nesse caso, o que motivou a ansiedade de Beatriz está presente no plano social, com a presença de outras pessoas. Percebe-se que a proposta da professora para 
que ela apresentasse oralmente para a turma provavelmente gerou mudanças psicológicas na aluna e a fez não ir à aula. Horwitz et al. (1986) afirmam que essa ação de faltar às aulas é recorrente em alunos com o nível alto de ansiedade como maneira de aliviar um pouco a tensão.

Apesar de toda a apreensão na hora de se comunicar, Beatriz afirma que se sente mais confortável quando se trata de uma atividade oral que ela pode fazer com algum colega mais próximo, um amigo. Ela afirma, também, que quando a atividade é feita com algum colega ao qual ela não esteja habituada ela se sente constrangida por acreditar estar atrapalhando o desenvolvimento do colega e por acreditar que o colega sabe mais do que ela, conforme assinalou na EASALE adaptada e reafirmou durante a entrevista:

Excerto 3. Atividades orais em pares ou pequenos grupos.

$\mathrm{Na}$ hora que tinha os trabalhos, aquela parte de treinar, quando era em grupo, eu ficava um pouco com vergonha quando eu não tava com... porque eu tinha uma amiga que fazia comigo, né? Aí, eu ficava com um pouco de vergonha quando era com outra pessoa, porque a sensação que eu sempre tive é que a outra pessoa sabia mais, era como se eu tivesse atrapalhando na hora de treinar. E a outra pessoa tinha que ficar "não, não é assim. Não, não é assim". Então o que me deixava um pouco assim pra ir pras aulas de inglês era saber que tinha esses diálogos, mesmo sabendo que é importante pra aprender o idioma. Eu me sentia desconfortável. [...]. Eu acho que a pessoa tem que tentar [falar], mesmo eu fazendo o contrário. Eu sei que eu tenho que falar, mas eu não falo porque eu não consigo (entrevista, 5 de maio de 2020).

Apesar de seu nervosismo e da vergonha na hora de se comunicar, conforme conferido também no BALLI adaptado, Beatriz é consciente acerca da importância do trabalho em grupo ou em dupla e da necessidade de se comunicar na LE para o desenvolvimento de sua oralidade, ou seja, Beatriz não quer fazer os trabalhos orais devido ao medo de avaliação negativa por parte do colega, demonstrada pela forma como o colega de classe reagia quando ela começava a falar, mas acredita na sua eficácia para aprender a falar o inglês.

Quando perguntada sobre seu desenho (ver anexo A), Beatriz relatou como se comporta nos trabalhos em dupla e demonstrou novamente 
Fico muito ansiosa: ansiedade, crenças e ações...

sua crença de que é preciso falar para se desenvolver oralmente na língua estudada:

\begin{abstract}
Excerto 4. Desenho.
Geralmente quando é trabalho em dupla assim, eu começo calada. Eu gosto mais de perguntar do que falar, entendeu? E eu fico agoniada aqui dentro assim, tá vendo? Tipo uma aflição, uma ansiedade, um frio na barriga. Podia ter riscado a barriga também. Agonia, sabe? [...] Eu sei que tenho que falar e eu não falo, tá vendo que coloquei um x na boca? (desenho, 12 de maio de 2020).
\end{abstract}

Notamos que a apreensão que ela sente resultou no ato de desenhar o "x" na boca, o que significa "não falar", mesmo tendo a consciência de que deveria falar, conforme visto, também, no BALLI adaptado e na entrevista. Em outras palavras, a apreensão sentida pela aprendiz delimitou seu esforço e comportamento em sala (GREGERSEN et al., 2014). Ainda, Beatriz, cujo coração bate forte no momento da fala, riscou o coração, relatando que queria marcar também a barriga, justamente porque sente um frio na barriga ao falar em inglês, segundo os sintomas psicológicos mencionados por Horwitz et al. (1986). Ou seja, para ela o " $x$ " significa o ato de não falar em inglês, enquanto os riscos representam a ansiedade que sente em sala de aula.

Dessa forma, percebemos que o que causa a ansiedade de Beatriz está no fato de ela ter de se expressar oralmente, seja para a turma inteira, em grupos menores ou em dupla. Essa ansiedade que ela sente é tão intensa que gera uma ação: ficar calada em sala de aula e faltar à aula para não ter de participar desse tipo de atividade (comportamento do evitamento), mesmo acreditando em sua eficácia.

\title{
4.3.2 Medo de avaliação negativa e ansiedade de provas
}

Ao se comunicar em inglês, a participante demonstra medo de ser considerada pelo grupo uma pessoa que não entende coisas simples e afirma que se fosse corrigida apenas pelo professor seria mais aceitável. Juntamente com o medo de ser avaliada pelos colegas de turma, vem o receio de errar, de ser corrigida na frente dos colegas: 
Excerto 5. Medo de avaliação.

[os colegas] Julgando "ah, não sabe! Um negócio tão simples você não entendeu." Igual quando aluno fala "professor, não entendi", aí os outros falam "lá vem fulano de novo, que nunca entende e não sabe de nada" (risos), fico com medo de ser essa pessoa, sabe? Me preocupando de ser essa pessoa. [...]. É assim, o professor falando assim, se for, por exemplo, eu e o professor e o professor me corrigindo, eu me sinto tranquila. Agora vamos supor, é uma avaliação pra turma toda, aí o professor corrige tudo que eu falo e eu falo errado na frente de todo mundo, fala se não é vergonhoso (entrevista, 5 de maio de 2020).

Apesar do medo de errar e de ser corrigida na frente de outros colegas, Beatriz destaca o feedback corretivo como necessário para a aprendizagem, mas, ao mesmo tempo, ela prefere que não a corrijam por receio de errar muito:

Excerto 6. Crença sobre o feedback corretivo.

eu acho que [correção] é importante, porque como é que eu vou evoluir se eu não sei se tá certo, se tá errado. [...]. Se [o professor] for corrigir todos os meus erros, imagina! Vai ser tudo. Aí vai ser muito frustrante (entrevista, 5 de maio de 2020).

Beatriz é contraditória quanto ao que acredita e ao que faz. Barcelos (2004) afirma que nem sempre a pessoa irá agir de acordo com o que acredita, demonstrado a natureza paradoxal das crenças.

Outra razão de ansiedade nas aulas de língua inglesa para Beatriz são as provas, principalmente as de produção e compreensão oral. Ela mostrou seu desconforto nas provas na EASALE adaptada e reafirma durante a entrevista:

Excerto 7. Ansiedade de provas.

Eu fico nervosa em todas [as provas], mas na oral e no listening eu fico mais. [...] Porque o listening tem a quantidade de vezes, né? Não vai ter como repetir as vezes que eu quiser. Aí já dá aquele negócio... No oral, na prova oral é porque você tá lá, de cara com o professor. [...] No oral, na prova oral é porque você tá lá, de cara com o professor. [...] [me sinto] pressionada, insegura (entrevista, 5 de maio de 2020). 
Fico muito ansiosa: ansiedade, crenças e ações...

$\mathrm{Na}$ prova oral, Beatriz está se comunicando em inglês e sendo avaliada. Nessa situação, de acordo com Horwitz et al. (1986), dois tipos de ansiedade misturam-se: a apreensão comunicativa e a ansiedade de provas, e isso acaba criando um medo ainda maior do que ela sente na prova escrita, por exemplo. Na prova de compreensão oral, por ela não ter controle de quantas vezes o áudio será repetido, isso acaba lhe causando apreensão: a ansiedade receptiva (RUBIO ALCALÁ, 2004), pois tem medo de não conseguir compreender o que está sendo dito no áudio.

A ansiedade de provas gera comportamentos de evitamento em Beatriz. A participante afirmou que já faltou às provas e obteve nota zero por medo e disse que fica sem dormir quando sabe que está chegando o período das avaliações. Além disso, ela afirma que tem de compensar a nota da prova oral nas provas escritas, as quais ela chama de "prova de gramática", como mostra o excerto abaixo:

Excerto 8. Ações causadas pelo medo de provas.

É, realmente, me sinto bem desconfortável na prova oral e no listening e eu já faltei. Eu já sofro por antecipação quando eu sei que vai ter, eu já fico com uma agonia na barriga, sem dormir, ansiosa e já faltei várias vezes por conta disso. [...]. Mas, geralmente, eu faltava e era isso. E aí eu estudava para a prova de gramática, pra não ter que refazer [a prova oral devido à nota] (entrevista, 5 de maio de 2020).

Como exposto no quadro a seguir, Beatriz demonstra ansiedade quanto a algumas questões: medo de errar e ser corrigida na frente dos colegas; medo de acreditarem que ela não compreende coisas simples e medo de provas. Quanto às crenças, ela acredita que o feedback corretivo é importante e necessário para sua aprendizagem da língua inglesa. A ansiedade de provas da participante leva-a a tomar atitudes, tais como faltar à aula no dia da prova, e causa sintomas físicos, como a perda do sono por ansiedade. Por conseguinte, precisa estudar mais para a prova escrita a fim de compensar a nota das avaliações orais. 
Quadro 1 - Relação ansiedade, crenças e ações da participante

\begin{tabular}{|c|c|c|c|}
\hline Categoria & $\begin{array}{c}\text { Ansiedade de } \\
\text { Beatriz }\end{array}$ & Crenças de Beatriz & $\begin{array}{c}\text { Efeitos } \\
\text { de ansiedade } \\
\text { e crenças em seu } \\
\text { comportamento }\end{array}$ \\
\hline $\begin{array}{l}\text { Frustação e } \\
\text { apreensão } \\
\text { sobre a } \\
\text { oralidade }\end{array}$ & $\begin{array}{l}\text { Ter medo e } \\
\text { vergonha de falar } \\
\text { inglês em dupla, } \\
\text { grupos ou para a } \\
\text { turma; }\end{array}$ & $\begin{array}{l}\text { Comunicar-se em } \\
\text { duplas, grupos ou } \\
\text { para a turma é } \\
\text { importante para } \\
\text { melhor adquirir a } \\
\text { LE; }\end{array}$ & $\begin{array}{l}\text { Faltar à aula; } \\
\text { Evitar falar em } \\
\text { trabalhos em dupla; }\end{array}$ \\
\hline $\begin{array}{l}\text { Medo de } \\
\text { avaliação } \\
\text { negativa }\end{array}$ & $\begin{array}{l}\text { Medo de avaliação } \\
\text { negativa pelos } \\
\text { colegas, receio de } \\
\text { errar e de ser } \\
\text { corrigida na frente } \\
\text { deles; }\end{array}$ & $\begin{array}{l}\text { O feedback } \\
\text { corretivo é } \\
\text { necessário para } \\
\text { aprender a LE. }\end{array}$ & Evitar ser corrigida; \\
\hline $\begin{array}{l}\text { Ansiedade } \\
\text { de provas }\end{array}$ & $\begin{array}{l}\text { Medo de provas de } \\
\text { produção e } \\
\text { compreensão orais. }\end{array}$ & & $\begin{array}{l}\text { Faltar em dia de } \\
\text { prova; } \\
\text { Estudar mais para as } \\
\text { provas escritas para } \\
\text { compensar as notas } \\
\text { das provas orais. }\end{array}$ \\
\hline
\end{tabular}

Fonte: elaboração dos autores

\section{Considerações finais}

Recuperando o que foi inicialmente proposto na introdução, o objetivo geral desta pesquisa foi identificar a ansiedade, as crenças e as ações de uma aluna brasileira sobre a língua inglesa e sua aprendizagem. Para alcançarmos tal objetivo, traçamos duas perguntas para nos guiar no prosseguimento deste trabalho: (1) em que a aluna apresenta ansiedade e quais são suas crenças e ações sobre a língua inglesa e sua aprendizagem e (2) qual a relação entre ansiedade, crenças e ações dessa aluna quanto à sua aprendizagem de inglês. Assim, respondemo-nas neste ponto.

Percebemos que Beatriz apresenta ansiedade de realização (RUBIO ALCALÁ, 2004), a qual está relacionada ao medo de falhar ou de ser avaliada com resultados desfavoráveis, isto é, ela demonstra uma grande 
Fico muito ansiosa: ansiedade, crenças e ações...

apreensão ao ter de falar em inglês (HORWITZ et al., 1986), seja para a turma inteira, seja para grupos menores ou em dupla. Horwitz et al. (1986) alegam que se comunicar usando uma segunda língua é uma situação em que os adultos se arriscam, pois para fazê-lo é necessário ativar operações mentais complexas e não automáticas. Assim, o sentimento que Beatriz apresenta é de que está atrapalhando os colegas, pois acredita que eles sabem mais do que ela. Por isso, a participante tem medo de errar e de ser motivo de risos para os colegas. A ansiedade que ela sente, diante do medo e da apreensão relatados, se dá por meio de comportamentos psicológicos, tais como agonia, suor e frio na barriga. A ansiedade é um dos fatores afetivos que mais influenciam, de maneira negativa, a aprendizagem de uma LE (ARNOLD; BROWN, 2000). Dessa forma, o medo de Beatriz ao falar inglês e a crença de que os colegas seriam mais proficientes (GARDNER; MACINTYRE, 1993) levam a participante a uma ação negativa à sua aprendizagem: o comportamento do evitamento (HORWITZ et al., 1986), ou seja, não falar em inglês em sala de aula e faltar às aulas para se ver livre desse tipo de atividade. Isso nos ajuda a entender a relação entre sua ansiedade, crença e ação, conforme proposto na segunda pergunta de pesquisa.

Ademais, apesar de Beatriz acreditar que atividades em grupo e em dupla são necessárias para o desenvolvimento da oralidade e mesmo acreditando que o feedback corretivo é importante para sua aprendizagem da língua, ela não quer nem performar essas atividades, tampouco ser corrigida, pois tem receio que os colegas pensem que ela não compreende coisas simples, isto é, a aluna apresenta a ansiedade de língua estrangeira defendida por MacIntyre (2017), a qual é construída por fatores sociocontextuais. As crenças e as ações nem sempre serão compatíveis (BARCELOS, 2004).

Outra apreensão de Beatriz diz respeito ao medo de provas (HORWITZ et al., 1986) de compreensão e produção orais. A ansiedade de provas de Beatriz é tão intensa que a leva a faltar à aula em dia de prova, a perder o sono e a estudar mais para provas escritas para compensar a nota das provas orais.

Este estudo apresentou-se em caráter preliminar, por isso se limitou a fazer levantamento e a relacionar a ansiedade, as crenças e as ações da participante. Esperamos que com esta pesquisa não só Beatriz mas outros aprendizes também reflitam acerca de seus anseios, medos, crenças e ações 
quanto à aprendizagem de língua estrangeira e que, se necessário, apresentem uma postura crítica em que consigam perceber a melhor maneira de se aprender uma língua estrangeira e que se possa fazer algo para reverter a ansiedade que sentem. Além do mais, os professores podem diagnosticar a ansiedade dos alunos e, com isso, podem trabalhar de forma que essa emoção seja reduzida, fazendo-os entender que as situações de ansiedade à LE podem ser breves e não problemas que persistirão. Os docentes podem agir para redução da ansiedade tomando atitudes como diminuir a competitividade em sala de aula, deixar os alunos cientes dos objetivos das aulas e ajudá-los a desenvolver estratégias para traçar esses objetivos, aplicar provas com exercícios que sejam familiares aos alunos, utilizar músicas e jogos para relaxá-los, entre outros (OXFORD, 2000).

Diante do exposto, é necessário que se investiguem as ansiedades, as crenças e as ações de outros alunos brasileiros para que compreendamos melhor o que está sendo obstáculo na aprendizagem deles (BARCELOS, 2007) e como funcionam seus sistemas de crenças. Para isso, sugerimos mais estudos acerca da ansiedade, das crenças e das ações dos alunos nas mais diversas habilidades, não apenas na habilidade de fala, bem como estudos que procurem fazer com que o aprendiz tome uma postura críticoreflexiva quanto à sua aprendizagem para que possamos acompanhar uma possível mudança quanto à sua ansiedade, às suas crenças e às suas ações, uma vez que as crenças são dinâmicas e, por isso, podem variar através do tempo e espaço (KALAJA; BARCELOS, 2016). Assim, com o nível de ansiedade mais baixo, o aluno pode se desenvolver melhor no idioma (KRASHEN, 1982), atingindo o nível de proficiência esperado.

\section{Referências}

ANDRÉ, M. E. D. A. Etnografia da prática escolar. Campinas: Papirus, 2012.

ARNOLD, J.; BROWN, H. D. A map of the terrain. In: ARNOLD, J. (Org.). Affect in language learning. Cambridge: Cambridge University Press, 1999. 
Fico muito ansiosa: ansiedade, crenças e ações...

BARCELOS, A. M. F. Metodologia de pesquisa das crenças sobre aprendizagem de línguas. Revista Brasileira de Linguística Aplicada, Belo Horizonte, v. 1, n. 1, p. 71-92, 2001.

BARCELOS, A. M. F. Crenças sobre aprendizagem de línguas, Linguística Aplicada e ensino de línguas. Linguagem \& Ensino, v. 7, n. 1, p. 123-156, 2004.

BARCELOS, A. M. F; VIEIRA-ABRAHÃO, M. H. (Org.). Crenças $e$ ensino de línguas: foco no professor, no aluno e na formação de professores. Campinas: Pontes Editores, 2006.

BARCELOS, A. M. F. Reflexões acerca da mudança de crenças sobre ensino e aprendizagem de línguas. Revista Brasileira de Linguística Aplicada, v. 7, n. 2, p. 111-138, 2007.

BARCELOS, A. M. F. Desvelando a relação entre crenças sobre ensino e aprendizagem de línguas, emoções e identidades. In: GERHARDT, A. F. L. M.; AMORIM, M. A.; CARVALHO, A. M. (Org.). Linguística Aplicada e ensino: língua e literatura. Campinas: Pontes Editores, 2013. p. 153-186.

BARDIN, L. Análise de conteúdo. Lisboa: Edições 70, 1977.

BATTISTELLA, T. R. Os efeitos das emoções no ensino-aprendizagem de inglês e na formação do futuro professor: uma análise com base no feedback corretivo oral. Revista Horizontes de Linguística Aplicada, ano 14, n. 2, p. 91-111, 2015.

CONCEIÇÃO, M. P. Vocabulário e consulta ao dicionário: analisando as relações entre experiências, crenças e ações na aprendizagem de LE. Belo Horizonte, MG, 2004, 287f. Tese (Doutorado em Linguística Aplicada) Faculdade de Letras, Universidade de Minas Gerais.

CRESWELL, J. W. Research design: qualitative, quantitative, and mixed methods approaches. 3. ed. Thousand Oaks, California: SAGE Publications, 2009. 
Karolina Morais; Yûki Mukai

GARDNER, R. C.; MACINTYRE, P. D. A student's contribution to Second Language Learning: Part II, Affective Factors. Language Teaching, v. 26, p. 1-11, 1993.

GIL, A. C. Como elaborar projetos de pesquisa. 6. ed. São Paulo: Atlas, 2017.

GREGERSEN, T.; MACINTYRE, P. D.; MEZA, M. D. The Motion of Emotion: Idiodynamic Case Studies of Learners' Foreign Language Anxiety. The Modern Language Journal, v. 98, p. 574-588, 2014.

HORWITZ, E. K. Surveying students' beliefs about language learning. In: WENDEN, A.; RUBIN, J. (Org.). Learner strategies in language learning. London: Prentice Hall International, 1987. p. 110-129.

HORWITZ, E. K.; Horwitz, M. B.; COPE, J. A. Foreign language classroom anxiety. The Modern Language Journal, v. 70, n. 2, p. 125-132, 1986.

KALAJA, P.; BARCELOS, A. M. F.; ARO, M.; ROUHOTIE-LYTHY, M. Key issues relevant to the studies to be reported: Beliefs, Agency and Identity. In: KALAJA, P.; BARCELOS, A. M. F.; ARO, M.; ROUHOTIELYTHY, M. (Org.) Beliefs, agency and identities in foreign language learning and teaching. United Kingdom: Palgrave Macmillan, 2016. p. 823.

KALAJA, P.; DUFVA, H.; ALANEN, R. Experimenting with visual narratives. In: BARKHUIZEN, G. (Org.). Narrative research in applied linguistics. Cambridge: Cambridge University Press, 2013. p. 105-131.

KRASHEN, S. D. Second Language Acquisition Theory. In.: KRASHEN, S. D. Principles and practice in second language acquisition. Oxford: Pergamon Press, 1982. p. 9-56.

KRASHEN, S. D. The input hypothesis: issues and implications. 4. ed. New York: Longman, 1985. 
Fico muito ansiosa: ansiedade, crenças e ações...

KRASHEN, S. D. Applying the comprehension hypothesis: some suggestions. International Journal of Language Teaching, v. 1, p. 21-29, 2004.

LARSEN-FREEMAN, D.; LONG, M. H. An introduction to second language acquisition research. Londres: Longman Group UK Limited, 1991.

LÜDKE, M.; ANDRÉ, M. E. D. A. Pesquisa em educação: abordagens qualitativas. São Paulo: EPU, 1986.

MACINTYRE, P. D. An overview of language anxiety research and trends in its development. In: GKONOU, C.; DAUBNEY, M.; DEWAELE, J. M. (Org.). New insights into language anxiety: theory, research and educational implications. Bristol: Multilingual Matters, 2017.

MCCROSKEY, J. C. Oral communication apprehension: a summary of recent theory and research. Human communication research, v. 4, p. 78-96, 1977.

OXFORD, R. L. La ansiedad y el alumno de idiomas: nuevas ideas. In: ARNOLD, J. (Org.). La dimensión afectiva en el aprendizaje de idiomas. Traducción de Alejandro Valero. Madrid: Cambridge Universsity Press, 2000.

PRODANOV, C. C.; FREITAS, E. C. Metodologia do trabalho científico: métodos e técnicas da pesquisa e do trabalho acadêmico. 2. ed. Novo Hamburgo: Feevale, 2013.

RUBIO ALCALÁ, F. D. La ansiedade en el aprendizaje de idiomas. Huelva: Universidade de Huelva, 2004.

SANTOS, J. C. dos; BARCELOS, A. M. F. "Não sei de onde vem essa timidez, talvez um medo de parecer ridículo": um estudo sobre a timidez e a produção oral de alunos de inglês. Revista Horizontes de Linguística Aplicada, ano 17, n. 2, p. 15-38, 2018. 
STAKE, R. E. Qualitative case studies. In: DENZIN, N. K., LINCOLN, Y. S. (Org.). The SAGE Handbook of Qualitative Research. 3. ed. Sage Publications, 2005. p. 443-466.

VIEIRA-ABRAHÃO, M. H. Metodologia na investigação das crenças. In: BARCELOS, A. M. F.; VIEIRA-ABRAHÃO, M. H. (Org.). Crenças e ensino de línguas: foco no professor, no aluno e na formação de professores. Campinas: Pontes, 2006. p. 219-231.

YIN, R. K. Estudo de caso: planejamento e métodos. Porto Alegre: Bookman, 2015.

\section{Apêndice A - BALLI adaptado}

1. É mais fácil para crianças do que para adultos aprender línguas.

2. Algumas pessoas têm uma habilidade especial para aprender língua estrangeira.

3. Algumas línguas são mais fáceis que outras.

4. Inglês é

(a) uma língua muito difícil;

(b) uma língua difícil;

(c) uma língua de nível médio de dificuldade;

(d) uma língua fácil;

(e) uma língua muito fácil.

5. Eu acredito que vou aprender a falar inglês muito bem.

6. É importante falar inglês com uma excelente pronúncia.

7. Você não deve falar nada em inglês até que você saiba falar corretamente.

8. É mais fácil para alguém que já fala uma língua estrangeira aprender outra.

9. É melhor aprender inglês em um país em que se fala inglês.

10. É bom praticar inglês com nativos.

11. Eu fico com vergonha de falar inglês com outras pessoas.

12. A parte mais importante de aprender uma língua estrangeira é aprender a gramática. 
Fico muito ansiosa: ansiedade, crenças e ações...

13. A parte mais importante de aprender uma língua estrangeira é aprender o vocabulário.

14. É mais fácil falar do que entender inglês.

15. É mais fácil ler e escrever em inglês do que falar e entender.

16. A parte mais importante de aprender inglês é aprender como traduzir para minha língua materna.

17. Todo mundo pode aprender uma língua estrangeira.

18. Eu quero aprender a falar inglês bem.

\section{Apêndice B - EASALE adaptada}

1. Nunca me sinto totalmente seguro quando falo na minha aula de inglês.

2. Não me preocupo em cometer erros na aula de língua inglesa.

3. Tremo quando sei que vou ser chamado na aula de inglês.

4. Me assusta quando não entendo o que o professor está dizendo em inglês.

5. Não me incomodaria em ter mais aulas de línguas inglesa.

6. Durante a aula de inglês, eu me pego pensando em coisas que não têm nada a ver com o curso.

7. Fico pensando que os outros alunos são melhores em inglês do que eu.

8. Normalmente, me sinto à vontade durante os testes na minha aula de inglês.

9. Entro em pânico quando tenho que falar sem me preparar na aula de inglês.

10. Eu me preocupo com as consequências de reprovar na minha aula de inglês.

11. Eu não entendo por que algumas pessoas ficam tão chateadas com as aulas de língua inglesa.

12. Na aula de inglês, fico tão nervoso que esqueço as coisas que sei.

13. Fico com vergonha de me oferecer para responder algo voluntáriamente na minha aula de inglês.

14. Eu não ficaria nervoso ao conversar em inglês com falantes nativos.

15. Fico chateado quando não entendo o que o professor está corrigindo.

16. Mesmo se eu estiver bem preparado para a aula de inglês, sinto-me ansioso por isso. 
17. Eu frequentemente tenho vontade de não ir à aula de inglês.

18. Eu me sinto confiante quando falo na aula de língua estrangeira.

19. Fico com receio do meu professor de inglês estar pronto para corrigir todos os erros que eu cometer.

20. Eu posso sentir meu coração batendo forte quando vou ser chamado na aula de idiomas.

21. Quanto mais estudo para uma prova de inglês, mais confuso fico.

22. Não me sinto pressionado a ter que me preparar bem para a aula de inglês.

23. Eu sempre sinto que os outros alunos falam inglês melhor do que eu.

24. Eu me sinto muito constrangido em falar inglês na frente de outros alunos.

25. A aula de idiomas muda tão rápido que me preocupo em ficar para trás.

26. Sinto-me mais tenso e nervoso na minha aula de inglês do que nas minhas outras aulas.

27. Fico nervoso e confuso quando falo na minha aula de inglês.

28. Quando estou indo para a aula de inglês, sinto-me muito seguro e relaxado.

29. Fico nervoso quando não entendo cada palavra que o professor diz.

30. Sinto-me oprimido pelo número de regras que você precisa aprender para falar inglês.

31. Fico com receio de que os outros alunos riam de mim quando falo em inglês.

32. Eu provavelmente me sentiria confortável com falantes nativos de inglês.

33. Fico nervoso quando o professor de inglês faz perguntas que não preparei com antecedência. 
Fico muito ansiosa: ansiedade, crenças e ações...

Anexo A - Narrativa visual: o que é aprendizagem de inglês para mim

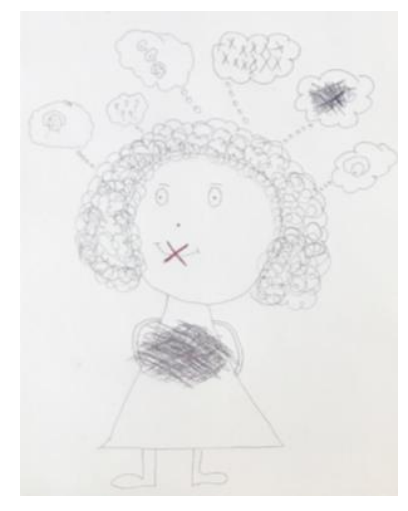

Recebido em: 28/07/2020

Aceito em: 06/11/2020

Title: I get very anxious: anxiety, beliefs, and actions of a Brazilian student about learning English as a foreign language 